\title{
Exploring the Impact of Retention Strategies on job Satisfaction and Organizational Commitment in Commercial Banks of Khyber Pakhtunkha, Pakistan
}

\author{
YASIR KHAN \\ PhD Scholar Qurtuba University Peshawar, Pakistan \\ yasirok62@yahoo.com \\ MUHAMMAD SHAFIQ GUL \\ Assistant Professor, COMSATS, Attock \\ mshafiqg@ciit-attock.edu.pk \\ MUKHARIF SHAH \\ Lecturer Institute of Business Studies and Leadership \\ Abdul Wali Khan University Mardan \\ Mukharif28_shah@yahoo.com
}

\begin{abstract}
This research has been conducted at knowing the effects of retention strategies on job satisfaction and employees commitment. This research was conducted employees of this sector switching more often to other banks, as this sector is very volatile and all banks prefer to use most effective retention strategies in better dealing, satisfying and committing employees. This research will really help the top level management in knowing the efficacy of its retention strategies worth. The data was collected through questionnaires used by other researchers for their studies before. The scale used has been mentioned in in the construct of this study. This research used job satisfaction and commitment as dependent variable and the retention strategies as independent variable. Reliability analysis conducted for the purpose of the reliability of the data.Thus the research achieved both of the hypotheses that the retention strategies have positively effectjob satisfaction and organizational commitment of employees.
\end{abstract}

Keywords: Retention Strategies, Job Satisfaction, Organizational Commitment, Banking

\section{Introduction} Sector, Regression, Reliability Analysis.

Retention, in fact, represents the percentage of employees who continue to remain in the organization. High levels of retention were desired in most job groups. Retention is the converse of turnover. Industry-wide and company in specific measures that track turnover rates reveal that most companies surveyed by the center for Organizational Research had turnover rates in the 15 to 50 percent range, though a sizable minority enjoyed single-digit turnover. If the employees knew what they were supposed to do in order to be considered for retention, the answer was time, training, temperament or talent. However, it is supposed that the most affecting tools in context of 
employees' retention were time and training. Similarly it is also necessary that the employee must be equipped with tools like training necessary to do their job well, otherwise they will look for other employer who provides them with such tools (Lesperance, 2001).

Ongori (2007) suggested that while selecting people from pool of candidates, it is advisable for the selection authority to add value to their interview process, heighten employee loyalty, build supportive peer relationships, and improve retention rates simultaneously through implementation of a team recruitment strategy. Employee's retention matters have deep effect on organizational issues such as training time and investment. Hence failing to retain a key employee is a costly proposition for an organization. It comes evident through various estimates that losing a middle manager in many organizations may cost up to five times of his salary, retention and attrition were neither good nor bad, but the important thing is to achieve the organization's goals and objectives (Robbins, 1998).

In the recent years, it has been observed that there was no prevailing issue of finding and keeping core employees, instead what changed was the way to get the job done. This has brought a significant shift in employees' thinking of work patterns than they normally used whilst generating an overall shift in workplace values. It shows the importance of understanding that this shift was essential to build a strong company while to keep saving on the payroll and that it ignoring will cost company otherwise (Williams 2004). This research is aimed at knowing the effects of retention strategies that banking sector on the employee's job satisfaction and employee's commitment toward organization.

\subsection{Problem Statement}

Employees' job satisfaction and organizational commitment are predictors of organizational productivity. Job satisfaction ensures employees retention which in turn results into continues in employees' job and culture expenditure over recruitment and framing again and again. Forgoing in view the research study will examine the impact of retention strategies on employee's job satisfaction and their commitment to organization.

\subsection{Purpose of the Research}

The purpose of this research is to evaluate the pivotal role of retention strategies on employee satisfaction with job and their commitment towards their organization. More specifically, the factors, which have a great influence on employee's affiliation with respect to the strategies used to be assessed.

\subsection{Significance of the Study}

This research would help to know about the retention strategies of the employees in banking industry of Pakistan. By reporting the role of retention strategies on job satisfaction and organizational commitment, the study will help the management in designing better HR policies in future that will instill and uphold organizational commitment and job satisfaction behavior of bankers switch to other job. To retain the employees of the organization the management has to design their HR policies in ways, which retain their employees for long term.so this research will help in better formulating retain strategies for these banks. 


\subsection{Research Objectives}

- To describe the prevailing perceptions of employee job satisfaction and organizational commitment.

- To analyze the practices and pattern of retention strategies in these Banks.

- To find a relationship between retention strategies and job satisfaction as well as organization commitment.

\section{Literature Review}

The world is having 'globalization' ground-breaking trends running in business, speedy engineering and market modifications, worldwide competitors, deregulation for example include introduced organizations within the brink where by weather resistant wrestle using these troubles continually. Simultaneously, they're also determined pertaining to applying as well as modifying such challenging trends towards something as well as facts get older culture (Lepak, \& Snell 1999). For this reason tumultuous enterprise natural environment, among the troubles struggling with numerous enterprise organizations may be the preservation associated with core workers. Within this facts get older culture has access at this point for you to knowledge-based facts whereby by these people obviously are aware that how people capital is actually highly valued as well as thought to be a key gamer as well as vital towards success associated with enterprises. Therefore there is a large development associated with competitors amid organizations pertaining to looking the best natural talent workers (Clarke, 2001). He also argued that it's popular for the fresh paradigm of businesses that there are a vital require, while making use of modern enterprise management practices, for you to productively encourage the workforce as well as maintain these workers who're hugely talented and guide survive organizational restructuring, downsizing, combination, reorganizing, or even re-engineering endeavors.

It is more popular in which staff turnover considers being the serious organizational phenomenon which isn't just important to organizations but additionally towards people and culture likewise. When it comes to organizational perspective, it is very crucial for them to realize that staff turnover may expense with regards to prospecting, teaching, socialization, and disruption, and various roundabout costs (Dessler, 1999). Sinha and Shukla (2013) suggested that this function of the supervisor is important. The perspective supervisor really should have the ability to review, fully grasp, and effectively take care of staff turnover.

\subsection{Retention Management - A Strategic Tool}

Retention management is considered to be new organizing as well as coherent course of action in which starts using testifying the employees when exactly employees become a member of a lending broker (Kraut \& Korman 1999). Studies revealed in which there have been numerous key factors which in turn act as traveling power in such type of administration and will possibly be managed congruently. In line with Korman (1999) these tools can make organizational lifestyle as well as composition, recruitment method, shell out gains beliefs, employee support packages, and profession improvement technique. Many researchers have recommended by way of investigation in which more than 70 percentage regarding H.R professionals suggest that employee maintenance crop 
up to be a primary company worry for virtually any operation, whilst 45 percentage regarding H.R professionals high light in which there were a rise throughout employee turnover during last 16 several weeks. That's the reason why with the current economic circumstances these H.R professionals explained employee maintenance to be a company internal problem.

\subsubsection{Compensation}

It is the normal procedure adopted by lots of businesses that they can frequently produce smart pay deals when compared with his or her competitors in the market. Such deals might include unique pay monthly premiums, additional bonuses or perhaps some other economic honors. Seeing that recognized by quite a few college students (Kitay and Lansburg, 1997) that any organization can see its pay structure which will clearly reveal all the things.

\subsubsection{Challenging Work}

It is quite interesting that higher experienced persons accept issues which often certainly undoubtedly are a optimistic indicator for just about any group. In addition they like this perform, needs to be intended within suitable fashion understanding that the converter should have adequate methods, offered taken care of and managed through a highly effective management. Ordinary strenuous scenario corporations are noticed increasing improving their performance, interactions, workflows, and groups to produce far more enjoyable ambiance and, certainly, the project (Phillips \& comnell, 2003). It is rather interesting which often increased ability persons accept to difficulties which often certainly undoubtedly are a helpful sign for virtually every group. In addition they doing this job must be created within just right method knowing that this converter really should have enough sources supplied managed together with managed simply by an efficient oversight. Of their standard tense situation firms emerged enhancing modernizing job, interactions, workflows, and the improvement of other studies (Phillips \& Comnell 2003).

\subsubsection{Work Relationships}

Clarke (2001) argued that essentially the most key elements which in turn provokes employees in which to stay a business is actually that exactly how strong their own interactions usually are along with other people with whom they operate. It is in the interest of firms to encourage team development and to help undertaking responsibilities that entail assist peers, also to accomplish all the options about sociable relationship both throughout or as soon as the career several hours, as talked about simply by Ferris et al (1999). In the event that a single beliefs this staff in the corporations that's recognized strong relationship amongst people, entire the idea goes towards company's typical interest. The idea becomes necessary that there should be efficient interactions among all organization. In this particular value firms also use survey and responses measures to name this means that may help interactions in normal operation of the business (Williams, 2004).

\subsubsection{Recognition}

Any time personnel within an organization think their own functions, efforts, and also efficiency contributions have been accepted and also valued through operators and 
other golden-agers, that is usually them to be choose. In fact, they need to think perception about outcome and also acknowledgement. It can be genuine in which payment in terms of monetary benefits gives acknowledgement yet there are some other ways like non-monetary benefits which in turn is issue. These kinds or type of acknowledgement can include perception of determination, and also inspiration through operators, down line and also friends, clients and the like (Lepak \& Snell 1999).

\subsubsection{Work/Life Balance}

For a lot of individuals, the idea turns very pertinent for many years the direction they maintain his or her personal priorities and the conditions which in turn permit these help to make choice for to leave and to stay in this company. It might rely upon individual's personal conditions thinking of his or her career priorities, wellness, area, household, and other personal requirements and responsibilities, which in turn fixed journey to help them to remain and leave the organization (Jack et all 2003). For example, there were a lot of firms which have been offering flexible agendas and operate agreements for their staff members.

\subsubsection{Communication}

Useful sales and marketing communications fit a very strong effect on individual's commitment about giving out involving making or remaining in the organization. Those tones up employees' identification using the firm and also aids construct believe in. There may be currently an escalating pattern about organizations in providing home elevators prices, objects, organizing plans, performance and changes of which affect employees' options for thinking (Ferris et al., 1999). In this age group of opposition there are various organizations that have stepped even more and gives like details of which their own workers want and will need by utilizing by for the most legitimate solutions (Dessler, 1999).

\subsection{Organizational Commitment}

For a few generations organizational commitment has become the center of research and investigation with context about particular person and organizational efficiency. During this time there are presented a few completely new kinds of organizational behavior including the actual advancement about completely new size about company and worker relationships and subconscious legal papers (Fierman, 1994). In this particular considered research investigation happened furthermore, in order to summarize the actual development about organizational commitment in a single or maybe several mean (Comnell, 2003).

The practice about employees' organizational commitment, essential for both profit and non-profit organization to led to successful endeavors. The companies have been likely to identify the actual strong expenses involving worker turnover since expenses coming from break up, replacement and teaching (Hamel, 1990; Braddock \& Mitchell, 1992). In context involving roundabout cost, Barak et al. (2001) possesses asserted these roundabout expenses tend to be connected with worker turnover which is much more challenging and complicated process to evaluate them. These researchers publish a report that this roundabout expenses develop generally from depriving situation of employees' proficiency. Therefore their particular co-workers' production is usually 
disturbed and reasons loss of production when a completely new worker find it difficult to accomplish the things with complete skill and determination.

\subsection{Job Satisfaction}

Lesperance (2001) identifies that job satisfaction is the person feeling about job. The pleased feeling is job satisfaction and implement feeling is the dissepimental. in line with your ex these kinds of optimistic mental thoughts result from awareness exactly how one particular senses that will his/her values, requirements, wants and also targets are usually content. Consequently career fulfillment can be considered to be expression of the person's worth ruling within framework connected with work-related benefits. Almost comparable explanation connected with career development and job satisfaction have been explained by means of Locke and also Henne whom are convinced that satisfaction could be the pleasant about job and is the expression through the achievements connected with one's career values inside the do the job scenario. Sinha and Shukla (2013) argued that job satisfaction and the parameters in which influence it, are actually the concentration associated with research workers and also management scholars intended for a lot more than eight generations. The niche features seized the interdisciplinary attention of men and women active in the aspects of her, organizational conduct, and also commercial mindsets since Elton Mayo and the Hawthorne scientific tests on the later 1920 s.

\subsection{Theoretical Framework}

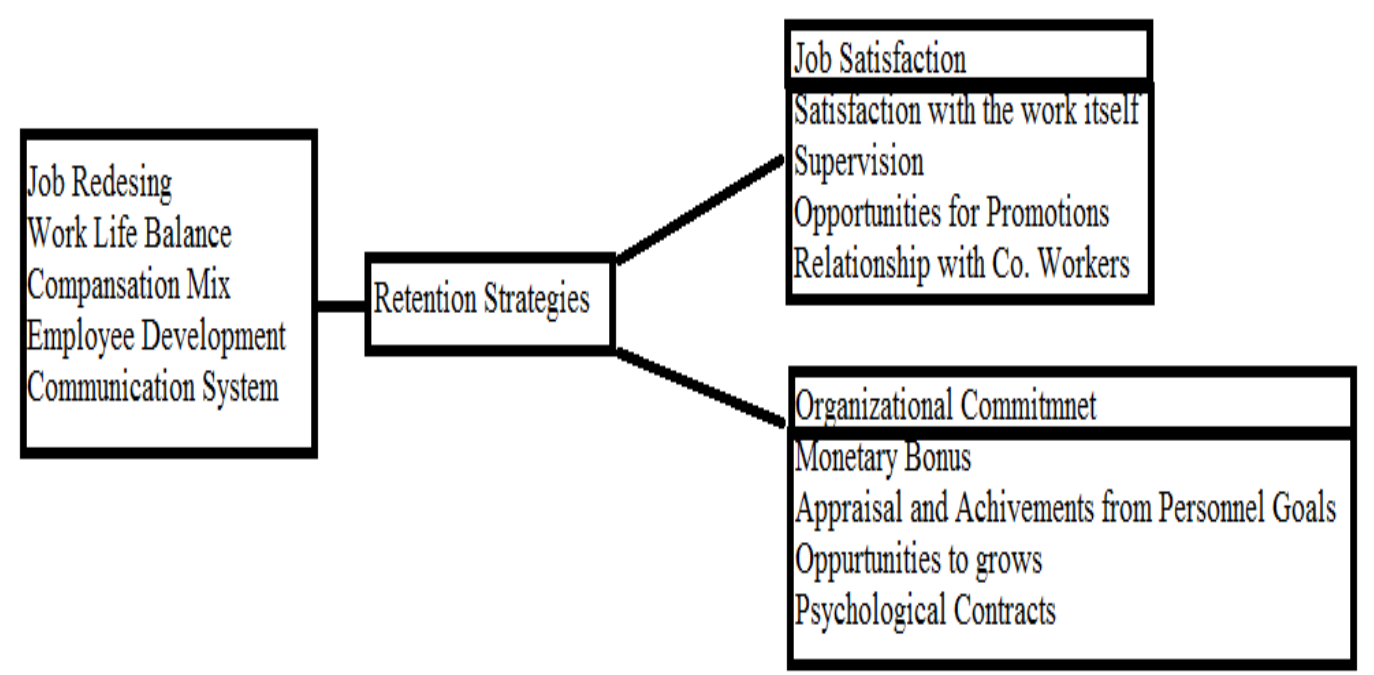

\subsection{Research Hypothesis}

Following are the hypothesis for the this research;

$\boldsymbol{H}_{1}:$ Employee retention strategies have positive impact on Employees job satisfaction. 
$\boldsymbol{H}_{2}$ : Employee retention strategies have positive impact on Employees organizational commitment.

\section{Research Methodology}

Keeping in view the type of research, it is quantitative research as the data of this research has been quantitatively analyzed.

\subsection{Population and sampling Techniques of Research}

Population for this research will be the employees of private banks of Pakistan.

Total 200 employees of the ten commercial banks have been used in the data collection of this research. The data collected from a sample of 200 employees (20 from each bank). Data has been collected form OG I and OG II.The non-probability convenience sampling technique has been used. The most easily accessible members chosen as subjects. The sample is enough to get an idea about different retention strategies carried out by different banks and the impact of these retention strategies on employees' commitment and job satisfaction. As there is one regional head office for each bank in Peshawar.

\subsection{Tools for Data Analysis}

The SPSS was used in the data analysis of this research study.

\subsection{Statistical Techniques}

This research study was based on using a number of statistical techniques like correlation, reliability analysis, Factor analysis and regression analysis used for the study.

\section{Data Analysis}

This chapter is comprised of Demographic analysis, Factor analysis, reliability analysis, and correlation and regression analysis.

\subsection{Demographics of the Research}

Table 1: Gender wise Distribution of Sample

\begin{tabular}{lll}
\hline Gender & Number & \%age \\
\hline Male & 10 & 80 \\
Female & 40 & 20 \\
Total & 200 & 100 \\
\hline
\end{tabular}

The above table indicating the number of respondents both male and female, which were considered in data collection. The results showing that total 160 male and 40 female respondents were analyzed for the results of this research study. As male and Female both were found as employees in the population of this research study.

Table: 4.2: Qualification Wise Distribution

\begin{tabular}{lll}
\hline Qualification & Number & \%age \\
\hline Masters & 180 & 90 \\
M.phil & 18 & 9 \\
Phd & 2 & 1 \\
Total & 200 & 100 \\
\hline
\end{tabular}


The above table showing the level of qualification in this current research study. The results suggest that almost 90 percent of the respondents were having master and only 9 percent M.Phil.Equaling and the only 1 percent respondents have done their Ph.D.

\subsection{Factor Analysis}

Table 3: KMO and Bartlett's Test Organizational Commitment

\begin{tabular}{lll}
\hline \multicolumn{2}{c}{ Kaiser-Meyer-Olkin Measure of Sampling Adequacy. } & .654 \\
\hline \multirow{3}{*}{ Bartlett's Test of Sphericity } & Approx. Chi-Square & 82.563 \\
& Df & 10 \\
& Sig. & .000 \\
\hline \multicolumn{2}{c}{ Table 4: KMO and Bartlett's Test Job satisfaction } \\
\hline Kaiser-Meyer-Olkin Measure of Sampling Adequacy. & .764 \\
Bartlett's Test of Sphericity & Approx. Chi-Square & 63.567 \\
& Df & 10 \\
& Sig. & .000 \\
\hline
\end{tabular}

Table 5: KMO and Bartlett's Test turn over intention

Kaiser-Meyer-Olkin Measure of Sampling Adequacy. .774

Bartlett's Test of Sphericity

Approx. Chi-Square $\quad 70.563$

\begin{tabular}{ll} 
Df & 10 \\
Sig. & .000 \\
\hline
\end{tabular}
Table 6: Reliability Analysis

\begin{tabular}{cll}
\hline Variables & Items & Cronbach's Alpha \\
\hline Organizational commitment & 18 & 0.76 \\
Job satisfaction & 38 & 0.74 \\
Retention strategies & 14 & 0.81 \\
\hline
\end{tabular}

The above table showing the reliability of the variables organizational commitment, job satisfaction and retention strategies. The strength and reliability of the variables of the research should be known to judge its suitability for the collection of data (Ajai and Gaur, 2009) .The reliability was conducted to understand the reliability and effectiveness of the variables. For reliability acceptability of the variables needs to having value of .60 as the thresh hold value of the variable. The Cronbach's alpha values of all the variables are within the feasible ranges. The values of all variables i.e organizational commitment, job satisfaction and retention strategies are $0.76,0.74$ and 0.81 respectively. The results suggesting that data of this research is highly reliable. 
Table 7: Correlation Analysis

\begin{tabular}{llll}
\hline & TI & JS & OC \\
\hline TI & 1 & & \\
JS & $.376^{* *}$ & 1 & \\
OC & $.329^{* *}$ & $.350^{* *}$ & 1 \\
\hline
\end{tabular}

**. Correlation is significant at the 0.01 level (2-tailed).

The above table is the evidence of correlation analysis shoving the results of the variables of this research study. The value of correlation actually lies between +1 and -1 . The near the value to 1 meaning the stronger the correlation between the variables and the nearer the value to -1 meaning the weaker the correlation. The correlation results suggest that there is strong positive correlation in retention strategies, job satisfaction and organizational commitment.

\subsection{Regression Analysis}

As the regression analysis is used to know the impact of one variable upon another. The following two regression models have been used in this research study.

Table 8: The Impact of Retention strategies on Organizational commitment Predictor Organizational commitment

\begin{tabular}{rrrrrrrr} 
& B & $R$ & $R^{2}$ & Adj. $R^{2}$ & F. Value & t & P. Value \\
TI & .485 & .490 & .394 & .386 & 23.67 & 5.57 & .000 \\
\hline
\end{tabular}

The above table is showing results of regression analysis. Regression is used to understand the impact of one variable upon other variable. The $\mathrm{t}-\mathrm{value}=5.57$ suggest that retention strategies is statistically individually significant and has positive significant effect on organizational commitment.. As the critical value of t-test should be 2 . The Fvalue indicating about the overall significance level of the model. The model to be statistically significant should have f- value 4 or above.. The F-value $=23.67$ suggests that model of this research is highly significant. The co-efficient of determination (R-square) telling about that how many changes incurred due to changes in independent variable. The value of this is showing that 39 percent changes in dependent variable organizational commitment is brought by the retention strategies. The Beta value tells us about represent a unit change in independent variable cause how much change in dependent variable. The value of beta is .48 meaning that one unit change in variable retention strategies will bring about 48 percent change in dependent variable organizational commitment.

Table 9: The Impact of Retention Strategies on Job Satisfaction

\begin{tabular}{llllllll}
\hline \multirow{2}{*}{ Predictor } & \multicolumn{7}{c}{ Job Satisfaction } \\
\cline { 2 - 8 } TI & $\mathrm{B}$ & $R$ & $R^{2}$ & Adj. $R^{2}$ & F. Value & $\mathrm{t}$ & P. Value \\
& .444 & .330 & .344 & .328 & 28.98 & 6.23 & .000 \\
\hline
\end{tabular}

The above table is showing results of regression analysis. Regression is used to understand the impact of one variable upon other variable.. The $\mathrm{t}$ - value $=6.23$ suggest that retention strategies is statistically individually significant and has positive significant effect on organizational commitment.. As the critical value of t-test should be 2 . The F- 
value indicating about the overall significance level of the model. The model to be statistically significant should have f- value 4 or above. The F-value $=28.98$ suggests that model of this research is highly significant. The co-efficient of determination (R-square) telling about that how many changes incurred due to changes in independent variable. The value of this is showing that 34 percent changes in dependent variable organizational commitment is brought by the retention strategies. The Beta value tells us about represent a unit changes in independent variable cause how much change in dependent variable. The value of beta is .44 meaning that one unit change in variable retention strategies will bring about 44 percent change in dependent variable organizational commitment.

\section{Conclusion}

This research was conducted understanding the impact of retention strategies on the job satisfaction and organizational commitment. This research study was conducted analyzing the employees of commercial banks in KPK. As these organizations are key organizations and research was needed to put something in the body of knowledge of the top level mangers and officers in these organizations. Total 200 employees considered as sample for this research study. The data of this research was collected through questionnaires used by other researchers for their studies before this research .This research was conducted using retention strategies as independent variable and job satisfaction and organizational commitment as independent variable... Reliability analysis, factor analysis, correlation and regression analysis were used for the analysis of the data. The reliability test showed that data used in this research is highly reliable as all the values are well above the acceptable range. The correlation showed that the retention strategies in these banks have positive association with job satisfaction and organizational commitment. The correlation value is well above the acceptable range, and all showed significant values. The regression was used to know the impact of retention strategies on job satisfaction and organizational commitment. The results of the both models showed significant results that retention strategies effect the job satisfaction and organizational commitment positively. Thus the results achieved both of the hypothesis developed for this research.

\section{References}

Clarke, K. F. (2001). What businesses are doing to attract and retain employee becoming an employer of choice. Employee Benefits Journal, 34-37.

Dessler, G. (1999). How to Earn your Employees Commitment. Academy of Management Executive, 13(2).58-59.

Ferris, G.F., Hochwarter, W. A., Buckley, R. M., Harrell, C. G. \& Frink, D. D. (1999). Human resources management: some new directions. Journal of Management, 25(3), 385

Fierman, J. (1994). The Contingency Workforce. Fortune, 30-36.

Hamel, G. \& Prahalad, C.K. (1990).The core competence of the corporation. Harvard Business Review, 68, 79-91.

Kissler, G. D. (1994). The New Employment Contract. Human Resource Management, $33(3), 335-52$. 
Kitay, J. \& Lansburg, R. (1997). Changing Employment Relation in Australia, Melbourne.Oxford University Press.

Kraut, J. \& Korman, P. (1999). Evolving Practices in Human Resource Management. Jossey Bass, San Francisco.

Lepak, D. P. \& Snell, S.A. (1999). The human resource architecture: toward a theory of human capital allocation and development. Academy of Management Review, 24(1), 31-32.

Lesperance, M.A. (2001). Multi-level Human Resource Management Strategy Key to Flexible Staffing Success. Research forum, HR professional,.35-39.

Ongori, H. (2007). A Review of the Literature on Employee Turnover. African Journal of Business Management pp. 049-054

Phillips, J.J. \& Comnell, A. O. (2003). Managing Employee Retention: A Strategic Accountability Approach. Butterworth-Heinemann. Journal of Humanities And Social Science, Volume 11(5), PP 57-61

Robbins, S. P. (1998). Organizational Behavior. 8th.ed. New Jersey: Prentice Hall.

Sinha, A. \& Shukla, S. (2013). Employee Turnover in banking sector: Empirical evidence

Weiss, D., Dawis, R., England, G. \& Lofquist. L. (1967). Manual for the Minnesota Satisfaction Questionnaire, Vol. 22

Williams, J. (2004). Job Satisfaction and Organizational Commitment, a Sloan Work and Family Encyclopedia 